\title{
Discriminatory ability of simple OGTT-based beta cell function indices for prediction of prediabetes and type 2 diabetes: the CODAM study
}

\author{
Louise J. C. J. den Biggelaar ${ }^{1,2}$ • Simone J. S. Sep ${ }^{2,3}$ - Simone J. P. M. Eussen ${ }^{1,2,4}$ • \\ Andrea Mari $^{5}$ - Ele Ferrannini ${ }^{6}$ - Marleen M. J. van Greevenbroek ${ }^{2,3}$. \\ Carla J. H. van der Kallen ${ }^{2,3}$ • Casper G. Schalkwijk ${ }^{2,3}$ • Coen D. A. Stehouwer ${ }^{2,3}$ • \\ Pieter C. Dagnelie ${ }^{1,2,4}$
}

Received: 30 June 2016/Accepted: 11 November 2016/Published online: 8 December 2016

(C) The Author(s) 2016. This article is published with open access at Springerlink.com

\begin{abstract}
Aims/hypothesis The hyperglycaemic clamp technique and the frequently sampled IVGTT are unsuitable techniques to assess beta cell function (BCF) in large cohorts. Therefore, the aim of this study was to evaluate the discriminatory ability of simple OGTT-based BCF indices for prediction of prediabetes (meaning impaired fasting glucose and/or impaired glucose tolerance) and type 2 diabetes.

Methods Glucose metabolism status was assessed by $2 \mathrm{~h} 75 \mathrm{~g}$ OGTT at baseline ( $n=476$, mean age 59.2 years, $38.7 \%$ women) and after 7 years of follow-up $(n=416)$ in the Cohort on Diabetes and Atherosclerosis Maastricht (CODAM) study
\end{abstract}

Louise J. C. J. den Biggelaar and Simone J. S. Sep are joint first authors.

Electronic supplementary material The online version of this article (doi:10.1007/s00125-016-4165-3) contains peer-reviewed but unedited supplementary material, which is available to authorised users.

Louise J. C. J. den Biggelaar

louise.denbiggelaar@maastrichtuniversity.nl

1 Department of Epidemiology, Maastricht University, PO Box 616, 6200 MD Maastricht, the Netherlands

2 School for Cardiovascular Diseases (CARIM), Maastricht University, Maastricht, the Netherlands

3 Department of Internal Medicine, Maastricht University Medical Center, Maastricht, the Netherlands

4 School for Public Health and Primary Care (CAPHRI), Maastricht University, Maastricht, the Netherlands

5 CNR Institute of Neurosciences, Padua, Italy

6 CNR Institute of Clinical Physiology, Pisa, Italy
(1999-2009). Baseline plasma glucose, insulin and Cpeptide values during OGTTs were used to calculate 21 simple indices of BCF. Disposition indices (BCF index $\times$ Matsuda index), to compensate for the prevailing level of insulin resistance, were calculated for the BCF indices with the best discriminatory abilities. The discriminatory ability of the $\mathrm{BCF}$ indices was estimated by the area under the receiver operating characteristics curve (ROC AUC) with an outcome of incident prediabetes $(n=73)$ or type 2 diabetes $(n=60$ and $n=18$ cases, respectively, in individuals who were nondiabetic or had normal glucose metabolism at baseline).

Results For incident prediabetes $(n=73)$, all ROC AUCs were less than $70 \%$, whereas for incident type 2 diabetes, $\mathrm{I}_{30} / \mathrm{I}_{0}$, $\mathrm{CP}_{30} / \mathrm{CP}_{0}, \Delta \mathrm{I}_{30} / \Delta \mathrm{G}_{30}, \Delta \mathrm{CP}_{30} / \Delta \mathrm{G}_{30}$ (where I, CP and $\mathrm{G}$ are the plasma concentrations of insulin, C-peptide and glucose, respectively, at the times indicated), and corrected insulin response at $30 \mathrm{~min}$ had ROC AUCs over $70 \%$. In at-baseline non-diabetic individuals, disposition indices $\Delta \mathrm{I}_{30} / \Delta \mathrm{G}_{30}$, $\Delta \mathrm{CP}_{30} / \Delta \mathrm{G}_{30}$ and corrected insulin response at $30 \mathrm{~min}$ had ROC AUCs of over $80 \%$ for incident type 2 diabetes. Moreover, these BCF disposition indices had significantly better discriminatory abilities for incident type 2 diabetes than the Matsuda index alone.

Conclusions/interpretation BCF indices reflecting earlyphase insulin secretion have the best ability to discriminate individuals who will develop prediabetes and type 2 diabetes. Of these, $\Delta \mathrm{CP}_{30} / \Delta \mathrm{G}_{30}$, often referred to as the $\mathrm{C}$ peptidogenic index, performed consistently well.

Keywords Beta cell function · Discrimination · Indices · Insulin secretion · OGTT · Prediabetes · Receiver operating characteristics · Type 2 diabetes mellitus 


\begin{tabular}{|c|c|}
\hline \multicolumn{2}{|c|}{ Abbreviations } \\
\hline $\mathrm{BCF}$ & Beta cell function \\
\hline $\mathrm{CIR}_{x}$ & $\begin{array}{l}\text { Corrected insulin response measured } x \\
\text { min after the start of the OGTT }\end{array}$ \\
\hline CODAM & $\begin{array}{l}\text { Cohort on Diabetes and Atherosclerosis } \\
\text { Maastricht }\end{array}$ \\
\hline $\mathrm{CP}_{x}$ & $\begin{array}{l}\text { C-peptide response measured } x \text { min after the } \\
\text { start of the OGTT }\end{array}$ \\
\hline DI & Disposition index \\
\hline $\mathrm{G}_{x}$ & $\begin{array}{l}\text { Glucose response measured } x \text { min after the } \\
\text { start of the OGTT }\end{array}$ \\
\hline $\mathrm{I}_{x}$ & $\begin{array}{l}\text { Insulin response measured } x \text { min after } \\
\text { the start of the OGTT }\end{array}$ \\
\hline IQR & Interquartile range \\
\hline NGM & Normal glucose metabolism \\
\hline ROC & Receiver operating characteristics \\
\hline SQUASH & $\begin{array}{l}\text { Short Questionnaire to Assess } \\
\text { Health-enhancing Physical Activity }\end{array}$ \\
\hline
\end{tabular}

\section{Introduction}

Type 2 diabetes is characterised by reduced metabolic sensitivity to insulin and insufficient insulin secretion by pancreatic beta cells. Insulin resistance in itself is an insufficient cause of type 2 diabetes, because of the pancreatic beta cells' ability to compensate for the prevailing level of insulin resistance by increasing insulin secretion. However, if the beta cells are unable to compensate for the prevailing insulin resistance, hyperglycaemia arises and can cause a transition from NGM to prediabetes, and eventually to type 2 diabetes [1-3].

The assessment of beta cell function (BCF) in vivo is complex because of its interplay with other key variables in glucose homeostasis, i.e. blood glucose levels, insulin sensitivity and hepatic insulin extraction [2, 4]. The simplest methods for the assessment of BCF in epidemiological studies are those based on basal circulating levels of glucose, insulin and/or C-peptide, such as HOMA-B [5]. Fasting levels, however, cannot provide insight into the secretory response of beta cells to rising and falling glucose concentrations $[2,3,6]$. Alternative approaches are based on beta cell responses after administration of nutrients, often glucose. Intravenous approaches include the hyperglycaemic clamp technique and the frequently sampled IVGTT. However, disadvantages of these methods are complex protocols, high costs and the non-physiological route and pattern of glucose administration $[3,6]$.

Oral administration of nutrients, as applied during an OGTT or mixed-meal tolerance test, enables assessment of the insulin secretory response under more physiological conditions [6]. Both oral methods stimulate the incretin hormone effect and allow for the simultaneous assessment of BCF, insulin sensitivity and glucose metabolism status. The mixed-meal tolerance test most closely tracks the physiological responses that are expected to occur during an individual's normal day-to-day life (to a load of mixed nutrients). The OGTT, however, can be standardised more easily and is simple when it comes to administering the glucose load. Therefore, the OGTT is often the preferred method in large epidemiological studies.

Several simple BCF indices obtained from an OGTT have been proposed and validated against intravenous methods, with the major drawback of a non-physiologically triggered insulin secretory response in the latter. Therefore, the objective of this study was to compare available, simple OGTTbased BCF indices that use plasma concentrations of glucose, insulin and/or C-peptide to identify their ability to discriminate glucose metabolism status (normal glucose metabolism [NGM], prediabetes [meaning impaired fasting glucose and/or impaired glucose tolerance] and type 2 diabetes), which may approximate conceptually a more physiological aspect of BCF assessment.

\section{Methods}

Study population and design We used data from the Cohort on Diabetes and Atherosclerosis Maastricht (CODAM) study, a longitudinal observational study on the natural progression of glucose tolerance [7]. CODAM includes 574 individuals with an elevated risk of type 2 diabetes and cardiovascular disease [8], who were extensively characterised at baseline with regard to their lifestyle and cardiovascular and metabolic profile during two visits to the university's metabolic research unit. After a median follow-up period of 7.0 years (interquartile range [IQR] 6.9-7.1 years), 491 individuals participated in the follow-up measurements (overall attrition rate 14\%). The participants who withdrew from the study during follow-up had essentially the same baseline characteristics as the study cohort. The CODAM study was approved by the Medical Ethical Committee of the Maastricht University Medical Center, and all participants gave written informed consent.

For the present analyses, we excluded 83 individuals with previously diagnosed type 2 diabetes at baseline (defined as self-reported diagnosis and/or use of glucose-lowering medication) who did not undergo an OGTT as per the protocol, and 15 individuals because of incomplete OGTT data. This resulted in a study population of 476 individuals, with glucose metabolism ranging from NGM $(n=294)$ to prediabetes $(n=122)$ to newly diagnosed type 2 diabetes $(n=60)$, using the WHO criteria as specified below [9]. Longitudinal analyses were restricted to individuals without type 2 diabetes who participated in the follow-up measurements $(n=294$ NGM, $n=122$ prediabetes), of whom $73(24.8 \%)$ individuals with NGM progressed to prediabetes, and $17(5.8 \%)$ individuals with NGM and $46(37.7 \%)$ with prediabetes progressed to type 2 diabetes. 
OGTT and glucose metabolism status After an overnight fast $(>12 \mathrm{~h})$, venous blood samples were collected before and 30,60 and $120 \mathrm{~min}$ after ingestion of $75 \mathrm{~g}$ glucose. Plasma for the assessment of insulin and C-peptide was collected in EDTA tubes on ice, separated after centrifugation $\left(3000 \times g\right.$ for $15 \mathrm{~min}$ at $\left.4^{\circ} \mathrm{C}\right)$, and stored at $-80^{\circ} \mathrm{C}$ until the assays were performed. The time between collection and storage was less than $2 \mathrm{~h}$.

Insulin and C-peptide were measured by use of a custom Meso Scale Discovery duplex array (Meso Scale Discovery, Gaithersburg, MD, USA; www.mesoscale.com). In short, 96 well-plates, with capture antibodies against insulin and C-peptide patterned on distinct spots in the same well were supplied by the manufacturer. Samples $(10 \mu \mathrm{l} /$ well $)$, detection antibodies and read buffer for electrochemiluminescence were applied according to manufacturer's instruction, and plates were read using a SECTOR Imager 2400 (Meso Scale Discovery). The detection ranges of the assay were 35-25,000 pg/ml for insulin and 70-50,000 pg/ml for C-peptide. Interassay CVs for insulin and C-peptide were $9.7 \%$ and $7.9 \%$, respectively. Insulin and C-peptide values were converted from $\mathrm{pg} / \mathrm{ml}$ to $\mathrm{pmol} / \mathrm{l}$ using a molar mass of $5808 \mathrm{~g}$ for insulin and $3010 \mathrm{~g}$ for C-peptide. Plasma for the assessment of glucose was collected in $\mathrm{NaF} / \mathrm{KOx}$ tubes on ice. Glucose was measured by use of the hexokinase method (HK-G6PD method; Glucose HK 125; ABX Diagnostics, Montpellier, France).

Glucose metabolism status was defined according to the WHO 2006 criteria [9]: NGM (fasting plasma glucose $<6.1 \mathrm{mmol} / 1$ and $2 \mathrm{~h}$ post-load plasma glucose $<7.8 \mathrm{mmol} / \mathrm{l}$ ), prediabetes (fasting plasma glucose levels of 6.1-6.9 mmol/1 and/or $2 \mathrm{~h}$ post-load glucose levels of 7.8-11.1 $\mathrm{mmol} / \mathrm{l}$ ) and type 2 diabetes (fasting plasma glucose $\geq 7.0 \mathrm{mmol} / 1$ and/or $2 \mathrm{~h}$ post-load glucose $\geq 11.1 \mathrm{mmol} / \mathrm{l}$ ).

OGTT-derived measures of BCF Available OGTT-based $\mathrm{BCF}$ indices were extracted from the literature and included nine early-phase measures (based on the first $30 \mathrm{~min}$ of the OGTT), six late-phase measures (based on the fasting condition combined with the last $60-120 \mathrm{~min}$ of the OGTT) and two overall insulin secretion measures (based on all OGTT sampling points) (Table 1).

Kahn et al identified a hyperbolic relationship between insulin sensitivity and secretion [10]. The product of insulin sensitivity and insulin secretion is called the disposition index (DI) and reflects a measure of BCF corrected for the degree of insulin sensitivity. In this study, the Matsuda index was used as a measure of insulin sensitivity (Matsuda index: 10,000/ $\sqrt{\mathrm{G}_{0}} \times$ $\mathrm{I}_{0} \times$ mean $\mathrm{G} \times$ mean I; where $\mathrm{G}$ and I are the plasma glucose and insulin values, respectively, at the time indicated) [11].

The OGTT-based mathematical model of Mari et al [12] describes insulin secretion as the sum of two components. Glucose sensitivity describes the degree of pancreatic beta cell responsiveness to absolute blood glucose levels (glucose-insulin dose-response curve). The beta cell potentiation factor modulates the dose-response curve as a positive function of time in individuals with NGM. The second component of insulin secretion is beta cell rate sensitivity, which represents early-phase insulin release. We evaluated these mathematical model-based BCF indices as additional analyses as these BCF components cannot be assessed by simple BCF indices.

Study population characteristics Body height $(\mathrm{cm})$ and weight $(\mathrm{kg})$ were measured to the nearest $1 \mathrm{~cm}$ and $0.1 \mathrm{~kg}$ with the participants wearing light clothing and no shoes [7]. Total cholesterol, HDL-cholesterol and triacylglycerol were determined using enzymatic techniques (Roche Diagnostics, Mannheim, Germany). LDL-cholesterol was calculated using the Friedewald formula [13]. NEFA were assessed in EDTA plasma using an enzymatic colorimetric method (NEFA-C; Wako Chemicals, Neuss, Germany) [14]. Blood pressure was measured using an oscillometric precision blood pressure instrument (Maxi-Stabol 3; Speidel \& Keller, now Welch Allyn, Skaneateles Falls, NY, USA) [15]. Smoking status, medication use and the prevalence of a history of cardiovascular disease and cardiovascular events were determined by self-report [16]. Physical activity was measured by the validated Short Questionnaire to Assess Health-enhancing Physical Activity (SQUASH) [17].

Statistical methods All analyses were performed using the software package SPSS statistics version 22.0 for Windows (SPSS, IBM Corp, Armonk, NY, USA). Differences in median BCF across glucose metabolism groups were tested by Kruskal-Wallis and Mann-Whitney $U$ tests.

The primary outcome was the discriminatory ability of the $\mathrm{BCF}$ indices to predict prediabetes and type 2 diabetes. The discriminatory ability was assessed by use of the area under the receiver operating characteristics (ROC) curve with either non-prediabetes (i.e. NGM) or non-diabetes as the reference category. Differences between consecutively ranked ROC AUCs were tested by the algorithm developed by DeLong et al [18]. ROC AUCs of the DIs (the products of the BCF index and Matsuda index) were assessed for BCF indices with ROC AUCs of 0.70 or above for incident prediabetes and/or type 2 diabetes [19].

Additional analyses were performed to cross-sectionally evaluate the discriminatory abilities of the BCF indices for prevalent prediabetes and type 2 diabetes. Finally, the discriminatory ability of the mathematical model variables of Mari et al [12] were evaluated: beta cell glucose sensitivity, beta cell rate sensitivity and beta cell potentiation factor.

The confidence level used in the statistical analyses was $95 \%$, corresponding to a $p$ value of 0.05 . 
Table 1 OGTT-based indices of BCF

\begin{tabular}{|c|c|c|}
\hline $\mathrm{BCF}$ index & $\begin{array}{l}\text { Literature } \\
\text { reference }\end{array}$ & Calculation \\
\hline \multicolumn{3}{|l|}{ Fasting indices } \\
\hline HOMA-B1 (\%) & {$[5]$} & $\left(20 \times \mathrm{I}_{0}\right) /\left(\mathrm{G}_{0}-3.5\right)$ \\
\hline HOMA-B2 (\%) & {$[32]$} & Web-based calculator using the HOMA2 model [33] \\
\hline Insulin:glucose ratio $t_{0}$ & {$[34]$} & $\mathrm{I}_{0} / \mathrm{G}_{0}$ \\
\hline C-peptide:glucose ratio $t_{0}$ & {$[35]$} & $\mathrm{CP}_{0} / \mathrm{G}_{0}$ \\
\hline \multicolumn{3}{|l|}{ Early-phase indices } \\
\hline Insulin ratio $t_{30}$ & {$[36]$} & $\mathrm{I}_{30} / \mathrm{I}_{0}$ \\
\hline C-peptide ratio $t_{30}$ & {$[36]$} & $\mathrm{CP}_{30} / \mathrm{CP}_{0}$ \\
\hline Insulinogenic index $t_{30}$ & {$[35]$} & $\left(\mathrm{I}_{30}-\mathrm{I}_{0}\right) /\left(\mathrm{G}_{30}-\mathrm{G}_{0}\right)$ \\
\hline Modified insulinogenic index $t_{30}$ & {$[37]$} & $\left(\mathrm{I}_{30}-\mathrm{I}_{0}\right) /\left(\mathrm{G}_{30}\right)$ \\
\hline C-peptidogenic index $t_{30}$ & {$[35]$} & $\left(\mathrm{CP}_{30}-\mathrm{CP}_{0}\right) /\left(\mathrm{G}_{30}-\mathrm{G}_{0}\right)$ \\
\hline $\mathrm{CIR}_{30} \times 10^{-2}$ & {$[38]$} & $\mathrm{I}_{30}\left[\left[\mathrm{G}_{30} \times\left(\mathrm{G}_{30}-3.89\right)\right]\right.$ \\
\hline Stumvoll early-phase $\times 10^{-2}$ & {$[39]$} & $1283+\left(1.829 \times \mathrm{I}_{30}\right)-\left(138.7 \times \mathrm{G}_{30}\right)+\left(3.772 \times \mathrm{I}_{0}\right)$ \\
\hline BIGTT-AIR $_{0.30 .120} \times 10^{-2}$ & {$[40]$} & $\begin{array}{l}\operatorname{Exp}\left[8.20+\left(0.00178 \times \mathrm{I}_{0}\right)+\left(0.00168 \times \mathrm{I}_{30}\right)-\left(0.000383 \times \mathrm{I}_{120}\right)-\left(0.314 \times \mathrm{G}_{0}\right)-\right. \\
\left.\quad\left(0.109 \times \mathrm{G}_{30}\right)+\left(0.0781 \times \mathrm{G}_{120}\right)+(0.180 \times \operatorname{sex})-(0.032 \times \mathrm{BMI})\right]\end{array}$ \\
\hline BIGTT-AIR $_{0.60 .120} \times 10^{-2}$ & {$[40]$} & $\begin{array}{l}\operatorname{Exp}\left[8.19+\left(0.00339 \times \mathrm{I}_{0}\right)+\left(0.00152 \times \mathrm{I}_{60}\right)-\left(0.000959 \times \mathrm{I}_{120}\right)-\left(0.389 \times \mathrm{G}_{0}\right)-\right. \\
\left.\quad\left(0.142 \times \mathrm{G}_{60}\right)+\left(0.164 \times \mathrm{G}_{120}\right)+(0.256 \times \operatorname{sex})+(0.038 \times \mathrm{BMI})\right]\end{array}$ \\
\hline \multicolumn{3}{|l|}{ Late-phase indices } \\
\hline Stumvoll second phase & {$[39]$} & $287+\left(0.4164 \times \mathrm{I}_{30}\right)-\left(26.07 \times \mathrm{G}_{30}\right)+\left(0.9226 \times \mathrm{I}_{0}\right)$ \\
\hline Insulin ratio $t_{120}$ & {$[36]$} & $\mathrm{I}_{120} / \mathrm{I}_{0}$ \\
\hline C-peptide ratio $t_{120}$ & {$[36]$} & $\mathrm{CP}_{120} / \mathrm{CP}_{0}$ \\
\hline Insulinogenic index $t_{120}$ & {$[35]$} & $\left(\mathrm{I}_{120}-\mathrm{I}_{0}\right) /\left(\mathrm{G}_{120}-\mathrm{G}_{0}\right)$ \\
\hline C-peptidogenic index $t_{120}$ & {$[35]$} & $\left(\mathrm{CP}_{120}-\mathrm{CP}_{0}\right) /\left(\mathrm{G}_{120}-\mathrm{G}_{0}\right)$ \\
\hline $\mathrm{CIR}_{120} \times 10^{-2}$ & {$[38]$} & $\mathrm{I}_{120} /\left(\mathrm{G}_{120} \times\left(\mathrm{G}_{120}-3.89\right)\right)$ \\
\hline \multicolumn{3}{|l|}{ Overall indices } \\
\hline AUC insulin:glucose ratio & [41] & $\begin{array}{l}\left.\left[(30-0) \times\left(\mathrm{I}_{0}+\mathrm{I}_{30}\right) / 2\right]+\left[(60-30) \times\left(\mathrm{I}_{30}+\mathrm{I}_{60}\right) / 2\right]+\left[(120-60) \times\left(\mathrm{I}_{60} \times \mathrm{I}_{120}\right) / 2\right)\right] /[(30- \\
\left.0) \times\left(\mathrm{G}_{0}+\mathrm{G}_{30}\right) / 2\right]+\left[(60-30) \times\left(\mathrm{G}_{30}+\mathrm{G}_{60}\right) / 2\right]+\left[(120-60) \times\left(\mathrm{G}_{60} \times \mathrm{G}_{120}\right) / 2\right]\end{array}$ \\
\hline AUC C-peptide:glucose ratio & {$[41]$} & $\begin{array}{l}{\left[(30-0) \times\left(\mathrm{CP}_{0}+\mathrm{CP}_{30}\right) / 2\right]+\left[(60-30) \times\left(\mathrm{CP}_{30}+\mathrm{CP}_{60}\right) / 2\right]+\left[(120-60) \times\left(\mathrm{CP}_{60} \times \mathrm{CP}_{120}\right)\right.} \\
\quad / 2)] /\left[(30-0) \times\left(\mathrm{G}_{0}+\mathrm{G}_{30}\right) / 2\right]+\left[(60-30) \times\left(\mathrm{G}_{30}+\mathrm{G}_{60}\right) / 2\right)+((120-60) \times \\
\left.\left.\quad\left(\mathrm{G}_{60} \times \mathrm{G}_{120}\right) / 2\right)\right]\end{array}$ \\
\hline
\end{tabular}

BIGTT-AIR, beta cell function, insulin sensitivity and glucose tolerance testing; t, time point during OGTT, min in subscript

\section{Results}

The median age was similar across groups of glucose metabolism status at baseline (Table 2). The male to female ratio was higher in participants with type 2 diabetes. Median fasting and $2 \mathrm{~h}$ post-load plasma concentrations of glucose and insulin, and $\mathrm{HbA}_{1 \mathrm{c}}$ increased in the order NGM to prediabetes to type 2 diabetes, whereas median insulin sensitivity decreased with impairment of glucose metabolism. Furthermore, BP increased and the lipid profile worsened with impairment of glucose metabolism. In addition, the proportion of current smokers was lowest among individuals with type 2 diabetes, but individuals with prediabetes or type 2 diabetes were less physically active than individuals with NGM (Table 2).

Overall, the median values of all $\mathrm{BCF}$ indices differed statistically significantly by glucose metabolism status at baseline, reflecting the fact that impaired $\mathrm{BCF}$ went along with impairment of glucose metabolism (Table 3). For most indices, the largest proportional difference in BCF was observed between individuals with prediabetes and type 2 diabetes.

Incident prediabetes and type $\mathbf{2}$ diabetes Of the individuals with NGM or prediabetes at baseline, 63 (17 NGM and 46 prediabetes) progressed to type 2 diabetes at follow-up, and 73 individuals with NGM progressed to prediabetes at follow-up (Table 4).

ROC AUCs for incident type 2 diabetes revealed estimates higher than $70 \%$ for $\mathrm{I}_{30} / \mathrm{I}_{0}, \mathrm{CP}_{30} / \mathrm{CP}_{0}, \Delta \mathrm{CP}_{30} / \Delta \mathrm{G}_{30}$ and corrected insulin response at $30 \mathrm{~min}\left(\mathrm{CIR}_{30}\right)$, with $\mathrm{ROC}$ AUCs ranging between $74 \%$ and $81 \%$ (Table 4). Restricting the population to individuals who had NGM at baseline did 
Table 2 Baseline characteristics: individuals with NGM, prediabetes and newly diagnosed type 2 diabetes mellitus (T2DM)

\begin{tabular}{|c|c|c|c|}
\hline Variable & $\begin{array}{l}\text { NGM } \\
n=294\end{array}$ & $\begin{array}{l}\text { Prediabetes } \\
n=122\end{array}$ & $\begin{array}{l}\text { T2DM } \\
n=60\end{array}$ \\
\hline Age (years) & $59.7(53.0,64.2)$ & $60.8(55.3,64.9)$ & $60.1(56.3,64.1)$ \\
\hline Women, $n(\%)$ & $120(40.8)$ & $47(38.5)$ & $17(27.9)$ \\
\hline BMI $\left(\mathrm{kg} / \mathrm{m}^{2}\right)$ & $27.3(25.0,29.5)$ & $28.0(26.5,31.2)$ & $30.6(26.6,32.8)$ \\
\hline Current smoker, $n(\%)$ & $60(20.4)$ & $22(18.0)$ & $9(14.8)$ \\
\hline Physical activity $\left(10^{3} \times\right.$ METs/week $)$ & $6.54(3.94,8.94)$ & $5.10(2.79,8.46)$ & $5.64(3.73,7.78)$ \\
\hline Systolic BP (mmHg) & $133(122,146)$ & $141(132,155)$ & $145(136,158)$ \\
\hline Diastolic BP (mmHg) & $80.0(73.5,85.0)$ & $82.8(78.0,91.5)$ & $85.0(79.5,92.8)$ \\
\hline Antihypertensive medication, $n(\%)$ & $82(27.9)$ & $52(42.6)$ & $29(47.5)$ \\
\hline CVD, $n(\%)$ & $68(23.1)$ & $34(28.1)$ & $24(39.3)$ \\
\hline CVE, $n(\%)$ & $40(13.6)$ & $20(16.5)$ & $11(18.0)$ \\
\hline Total cholesterol (mmol/1) & $5.20(4.60,5.80)$ & $5.20(4.60,5.83)$ & $5.50(4.90,6.00)$ \\
\hline HDL-cholesterol (mmol/l) & $1.23(1.01,1.44)$ & $1.09(0.93,1.37)$ & $0.97(0.86,1.20)$ \\
\hline LDL-cholesterol (mmol/l) & $3.30(2.80,3.90)$ & $3.35(2.80,4.30)$ & $3.50(2.90,3.98)$ \\
\hline HDL:LDL ratio & $0.37(0.28,0.48)$ & $0.32(0.26,0.45)$ & $0.30(0.24,0.37)$ \\
\hline Triacylglycerol (mmol/l) & $1.20(0.90,1.60)$ & $1.60(1.10,2.10)$ & $1.90(1.30,2.65)$ \\
\hline NEFA (mmol/l) & $0.49(0.38,0.57)$ & $0.53(0.43,0.64)$ & $0.55(0.45,0.70)$ \\
\hline Lipid-lowering medication, $n(\%)$ & $44(15.0)$ & $24(19.7)$ & $9(14.8)$ \\
\hline $\mathrm{HbA}_{1 \mathrm{c}}(\%)$ & $5.70(5.40,5.90)$ & $5.80(5.60,6.10)$ & $6.40(5.90,6.90)$ \\
\hline $\mathrm{HbA}_{1 \mathrm{c}}(\mathrm{mmol} / \mathrm{mol})$ & $38.0(35.0,40.0)$ & $39.0(37.0,43.0)$ & $46.0(40.0,51.0)$ \\
\hline Fasting glucose (mmol/l) & $5.27(5.00,5.53)$ & $6.00(5.54,6.30)$ & $7.14(6.81,7.95)$ \\
\hline Fasting insulin (pmol/l) & $61.2(45.2,87.4)$ & $78.8(51.4,133)$ & $110(66.1,159)$ \\
\hline $2 \mathrm{~h}$ glucose $(\mathrm{mmol} / \mathrm{l})$ & $5.65(4.65,6.54)$ & $8.79(7.82,9.90)$ & $12.3(11.1,14.7)$ \\
\hline $2 \mathrm{~h}$ insulin $(\mathrm{pmol} / \mathrm{l})$ & $352(211,589)$ & $664(424,1176)$ & $744(489,1017)$ \\
\hline Matsuda index of insulin sensitivity & $3.57(2.45,4.95)$ & $2.46(1.39,3.63)$ & $1.45(1.09,2.66)$ \\
\hline
\end{tabular}

Values are expressed as median (IQR) or $n(\%)$

CVD, self-reported cardiovascular disease; CVE, self-reported cardiovascular event; MET, metabolic equivalent not materially alter the results; the same five $\mathrm{BCF}$ indices and $\mathrm{CP}_{0} / \mathrm{G}_{0}$ had ROC AUCs higher than 70\% (AUCs 70-84\%). For incident prediabetes, the ROC AUCs of all BCF indices were less than $70 \%$.

After calculating the DIs, the ROC AUCs for $\Delta \mathrm{I}_{30} / \Delta \mathrm{G}_{30}$, $\Delta \mathrm{CP}_{30} / \Delta \mathrm{G}_{30}$ and $\mathrm{CIR}_{30}$ had the best discriminatory abilities (Fig. 1; see electronic supplementary material [ESM] Fig. 1 for ROC characteristics). Moreover, for incident type 2 diabetes, these BCF DIs had significantly better abilities than the Matsuda index alone (Fig. 1a).

Additional analyses The ability of all BCF indices to crosssectionally discriminate between glucose metabolism groups was evaluated. ROC AUCs for type 2 diabetes revealed estimates higher than $70 \%$ for all early-phase indices, the latephase index $\mathrm{CIR}_{120}$ and the two overall insulin secretion indices (ESM Table 1). The five indices that were ranked highest in the prospective analyses for incident type 2 diabetes, in individuals who were non-diabetic or had NGM at baseline, also showed high ROC AUCs in the cross-sectional analyses, with ROC AUCs in the range 78-88\% and 82 $92 \%$, respectively. The three DIs that were ranked highest in the longitudinal analyses, $\Delta \mathrm{I}_{30} / \Delta \mathrm{G}_{30}, \Delta \mathrm{CP}_{30} / \Delta \mathrm{G}_{30}$ and $\mathrm{CIR}_{30}$, also had the best ROC AUCs in the cross-sectional analyses (data not shown).

In individuals who were non-diabetic or had NGM at baseline, only the mathematical model variable of beta cell glucose sensitivity was able to discriminate incident type 2 diabetes (ROC AUCs of $78 \%$ for both groups). Compared with the simple BCF indices, only the C-peptidogenic index had better discriminatory abilities than beta cell glucose sensitivity for predicting incident type 2 diabetes. ROC AUCs of rate sensitivity and potentiation factor ratio were less than $70 \%$ (data not shown).

\section{Discussion}

In this study, for incident prediabetes and type 2 diabetes, the discriminatory ability of available simple OGTT-based indices 
Table 3 Values of BCF indices according to glucose metabolism status at baseline

\begin{tabular}{|c|c|c|c|c|}
\hline $\mathrm{BCF}$ index & $\begin{array}{l}\text { NGM } \\
n=294\end{array}$ & $\begin{array}{l}\text { IGM } \\
n=122\end{array}$ & $\begin{array}{l}\mathrm{T} 2 \mathrm{DM} \\
n=60\end{array}$ & $p$ values $^{\mathrm{a}}$ \\
\hline \multicolumn{5}{|l|}{ Fasting indices } \\
\hline HOMA-B1 (\%) & $105.39(74.60,144.20)$ & $99.78(64.62,169.02)$ & $88.58(53.25,118.20)^{\dagger}$ & 0.037 \\
\hline HOMA-B2 (\%) & $96.90(76.70,119.35)$ & $92.00(67.20,133.83) *$ & $79.40(55.75,98.25)^{\dagger}$ & 0.001 \\
\hline $\mathrm{I}_{0} / \mathrm{G}_{0}$ ratio $^{\mathrm{b}}$ & $11.45(8.55,16.4)$ & $13.21(8.58,13.13)$ & $15.82(9.69,21.22)^{\dagger \S}$ & 0.007 \\
\hline $\mathrm{CP}_{0} / \mathrm{G}_{0}$ ratio $^{\mathrm{b}}$ & $0.12(0.95,0.15)$ & $0.13(0.10,0.18)$ & $0.14(0.12,0.17)^{\dagger \S}$ & 0.016 \\
\hline \multicolumn{5}{|l|}{ Early-phase BCF indices } \\
\hline $\mathrm{I}_{30} / \mathrm{I}_{0}$ ratio & $7.98(6.14,10.4)$ & $5.81(4.61,7.42)^{*}$ & $3.62(2.74,3.62)^{\dagger \S}$ & $<0.001$ \\
\hline $\mathrm{CP}_{30} / \mathrm{CP}_{0}$ ratio & $3.38(2.91,4.22)$ & $2.68(2.25,3.30)^{*}$ & $1.96(1.74,2.38)^{\dagger \S}$ & $<0.001$ \\
\hline$\Delta \mathrm{I}_{30} / \Delta \mathrm{G}_{30}$ ratio & $135.50(88.27,198.93)^{*}$ & $90.75(53.81,151.89)^{*}$ & $58.02(38.11,85.16)^{\dagger \S}$ & $<0.001$ \\
\hline$\Delta \mathrm{CP}_{30} / \Delta \mathrm{G}_{30}$ ratio & $0.49(0.33,0.66)$ & $0.30(0.23,0.42)^{*}$ & $0.19(0.15,0.26)^{\dagger \S}$ & $<0.001$ \\
\hline $\mathrm{CIR}_{30} \times 10^{-2}$ & $12.91(8.29,19.15)$ & $8.02(4.34,11.54)^{*}$ & $3.68(2.72,5.86)^{\dagger \S}$ & $<0.001$ \\
\hline Stumvoll first phase $\times 10^{-2}$ & $12.53(9.33,16.76)$ & $10.83(6.08,17.51)^{*}$ & $7.08(4.08,12.56)^{\dagger \S}$ & $<0.001$ \\
\hline BIGTT-AIR $_{0.30 .120} \times 10^{-2}$ & $29.64(21.98,43.84)$ & $24.11(15.36,37.02)^{*}$ & $17.33(11.77,24.90)^{\dagger \S}$ & $<0.001$ \\
\hline BIGTT-AIR $_{0.60 .120} \times 10^{-2}$ & $34.00(25.81,51.12)$ & $27.32(17.08,44.66)^{*}$ & $19.42(12.37,31.24)^{\dagger \S}$ & $<0.001$ \\
\hline \multicolumn{5}{|l|}{ Late-phase BCF indices } \\
\hline Stumvoll second phase & $330.71(258.45,431.44)$ & $310.64(187.11,457.80)^{*}$ & $239.06(152.97,358.97)^{\dagger}$ & $<0.001$ \\
\hline $\mathrm{I}_{120} / \mathrm{I}_{0}$ ratio & $5.60(3.77,8.27)$ & $8.42(5.94,11.7) *$ & $6.85(4.32,10.37)^{\dagger \S}$ & $<0.001$ \\
\hline $\mathrm{CP}_{120} / \mathrm{CP}_{0}$ ratio & $4.04(3.21,5.08)$ & $4.51(3.64,5.60)$ & $3.73(2.59,5.31)^{\S}$ & $<0.001$ \\
\hline$\Delta \mathrm{I}_{120} / \Delta \mathrm{G}_{120}$ ratio & $235.21(, 122.49,532.01)$ & $200.50(113.36,403.98)^{*}$ & $114.48(66.54,178.28)$ & 0.037 \\
\hline$\Delta \mathrm{CP}_{120} / \Delta \mathrm{G}_{120}$ ratio & $1.35(, 1.29,2.83)$ & $0.91(0.59,1.32)^{*}$ & $0.47(0.31,0.67)^{\dagger}$ & 0.009 \\
\hline $\mathrm{CIR}_{120} \times 10^{-2}$ & $35.21(21.38,60.71)$ & $17.45(11.13,31.92)^{*}$ & $7.29(4.42,7.29)^{\dagger \S}$ & $<0.001$ \\
\hline \multicolumn{5}{|l|}{ Overall indices } \\
\hline $\mathrm{I}_{\mathrm{AUC}} / \mathrm{G}_{\mathrm{AUC}}$ ratio & $62.03(45.50,86.60)$ & $56.71(35.91,93.40)^{*}$ & $42.27(26.70,63.07)^{\dagger}$ & $<0.001$ \\
\hline $\mathrm{CP}_{\mathrm{AUC}} / \mathrm{G}_{\mathrm{AUC}}$ ratio & $0.35(0.26,0.38)$ & $0.28(0.21,0.37)^{*}$ & $0.20(0.16,0.24)^{\dagger}$ & $<0.001$ \\
\hline
\end{tabular}

Values are expressed as median (IQR)

${ }^{\text {a }} p$ value of Kruskal-Wallis test

${ }^{\mathrm{b}} \mathrm{A}$ higher value indicates impairment of $\mathrm{BCF}$, unlike other $\mathrm{BCF}$ indices

*Statistically significant difference IGM vs NGM, $p$ value of Mann-Whitney $U$ test $<0.05 ;{ }^{\dagger}$ statistically significant difference T2DM vs NGM, $p$ value of Mann-Whitney $U$ test $<0.05$; ${ }^{\S}$ statistically significant difference T2DM vs IGM, $p$ value of Mann-Whitney $U$ test $<0.05$

BIGTT-AIR, beta cell function, insulin sensitivity and glucose tolerance testing; T2DM, type 2 diabetes mellitus

of BCF was evaluated after a median follow-up period of 7 years. Overall, early-phase indices of BCF, typically based on the insulin response in the first $30 \mathrm{~min}$ of the OGTT, performed best.

The better ability of early-phase BCF indices to discriminate glucose metabolism status is in line with previous validation studies, which used the frequently sampled IVGTT or incident type 2 diabetes as reference standards [20,21]. Moreover, this finding corresponds with an earlier and stronger deterioration of the early-phase secretory response in the pathogenesis of type 2 diabetes $[1,22]$. The BCF indices ranked highest in our study also performed well in the evaluations of Hanson et al [20] and Lorenzo et al [21]. In general, discriminatory abilities of $\mathrm{BCF}$ indices using $\mathrm{C}$-peptide were better than those using insulin in a similar formula. This can be explained by the fact that insulin concentrations assessed in peripheral blood do not perfectly reflect insulin secretion by the pancreas. Pancreatic beta cells secrete insulin into the portal vein perfusing the liver, where insulin is partially cleared prior to entering the peripheral circulation [2-4]. A more valid estimation of prehepatic insulin secretion can be obtained from C-peptide, which is co-secreted with insulin in equimolar amounts and avoids hepatic degradation [2-4].

For prediabetes, we observed a lower discriminatory ability of the BCF indices than was seen for type 2 diabetes. This probably reflects the gradual deterioration of $\mathrm{BCF}$ during the pathogenesis of type 2 diabetes. In prediabetic individuals, insulin secretion is still sufficient to compensate for a certain level of insulin resistance and to maintain glucose levels within the non-diabetic range $[2,23]$. In our data, more detailed analyses of the subtypes of prediabetes, i.e. impaired fasting glucose and impaired glucose tolerance, revealed a trend 
Table 4 Discrimination between individuals with incident type 2 diabetes mellitus (T2DM) or prediabetes in individuals who were NGM or non$\mathrm{T} 2 \mathrm{DM}$ at baseline

\begin{tabular}{|c|c|c|c|c|c|c|}
\hline BCF index & $\begin{array}{l}\text { Incident T2DM in at-baseline } \\
\text { Non-T2DM } \\
\text { Follow-up } \\
n=306 \text { non-T2DM } \\
n=63 \text { T2DM }\end{array}$ & Rank & $\begin{array}{l}\text { Incident T2DM in } \\
\text { at-baseline NGM } \\
\text { Follow-up } \\
n=17 \text { T2DM } \\
n=170 \text { NGM }\end{array}$ & Rank & $\begin{array}{l}\text { Incident prediabetes in } \\
\text { at-baseline NGM } \\
\text { Follow-up } \\
n=73 \text { prediabetes } \\
n=170 \text { NGM }\end{array}$ & Rank \\
\hline \multicolumn{7}{|l|}{ Fasting measures } \\
\hline HOMA-B1 & $52(44,61)$ & 20 & $64(48,81)$ & 9 & $54(46,62)$ & 15 \\
\hline HOMA-B2 & $52(43,60)$ & 21 & $65(48,82)$ & 8 & $53(45,62)$ & 16 \\
\hline $\mathrm{I}_{0} / \mathrm{G}_{0}$ ratio & $59(51,67)$ & 16 & $69(54,85)$ & 7 & $51(43,60)$ & 20 \\
\hline $\mathrm{CP}_{0} / \mathrm{G}_{0}$ ratio & $60(52,68)$ & 14 & $70(55,84)$ & 6 & $52(44,60)$ & 19 \\
\hline \multicolumn{7}{|l|}{ Early-phase BCF indices } \\
\hline $\mathrm{I}_{30} / \mathrm{I}_{0}$ ratio & $77(70,83)$ & 4 & $72(60,84)$ & 5 & $55(47,63)$ & $9-11$ \\
\hline $\mathrm{CP}_{30} / \mathrm{CP}_{0}$ ratio & $78(72,84)$ & 2 & $76(65,87)$ & 3 & $50(43,58)$ & 21 \\
\hline$\Delta \mathrm{I}_{30} / \Delta \mathrm{G}_{30}$ ratio & $74(68,81)$ & 5 & $73(61,85)$ & 4 & $59(51,67)$ & 5 \\
\hline$\Delta \mathrm{I}_{30} / \mathrm{G}_{30}$ ratio & $69(62,77)$ & 6 & $63(49,77)$ & 10 & $55(47,63)$ & $9-11$ \\
\hline$\Delta \mathrm{CP}_{30} / \Delta \mathrm{G}_{30}$ ratio & $81(75,86)$ & 1 & $84(75,93)$ & 1 & $62(54,70)$ & $2-3$ \\
\hline $\mathrm{CIR}_{30}$ & $77(71,83)$ & 3 & $77(67,87)$ & 2 & $61(53,68)$ & 4 \\
\hline Stumvoll early-phase $\times 10^{-2}$ & $62(54,71)$ & 10 & $52(36,69)$ & 18 & $55(47,63)$ & $9-11$ \\
\hline BIGTT $_{0.30 .120} \times 10^{-2}$ & $63(55,71)$ & 9 & $58(42,73)$ & 12 & $54(46,63)$ & $13-14$ \\
\hline BIGTT $_{0.60 .120} \times 10^{-2}$ & $61(52,69)$ & 12 & $51(33,69)$ & 20 & $57(49,65)$ & 6 \\
\hline \multicolumn{7}{|l|}{ Late-phase BCF indices } \\
\hline Stumvoll second phase & $60(52,69)$ & 13 & $50(33,67)$ & 21 & $54(46,63)$ & $13-14$ \\
\hline $\mathrm{I}_{120} / \mathrm{I}_{0}$ ratio & $60(52,67)$ & 15 & $51(35,66)$ & 19 & $63(55,71)$ & 1 \\
\hline $\mathrm{CP}_{120} / \mathrm{CP}_{0}$ ratio & $54(46,62)$ & 18 & $56(41,71)$ & 13 & $62(54,70)$ & $2-3$ \\
\hline$\Delta \mathrm{I}_{120} / \Delta \mathrm{G}_{120}$ ratio & $54(47,61)$ & 17 & $54(39,69)$ & 15 & $55(48,63)$ & 8 \\
\hline$\Delta \mathrm{CP}_{120} / \Delta \mathrm{G}_{120}$ ratio & $52(48,58)$ & 19 & $52(39,65)$ & 17 & $55(47,62)$ & 12 \\
\hline $\mathrm{CIR}_{120}$ & $65(57,73)$ & 8 & $56(40,72)$ & 14 & $52(45,60)$ & 17 \\
\hline \multicolumn{7}{|l|}{ Overall insulin secretion indices } \\
\hline $\mathrm{I}_{\mathrm{AUC}} / \mathrm{G}_{\mathrm{AUC}}$ ratio & $61(53,70)$ & 11 & $53(37,69)$ & 16 & $52(44,61)$ & 18 \\
\hline $\mathrm{CP}_{\mathrm{AUC}} / \mathrm{G}_{\mathrm{AUC}}$ ratio & $68(60,76)$ & 7 & $63(48,78)$ & 11 & $56(47,64)$ & 7 \\
\hline
\end{tabular}

ROC AUCs are expressed in \% (95\% CI)

'Rank' reflects the order of ROC AUC estimates from high to low. Differences between ranked ROC AUCs were not statistically significant BIGTT-AIR, beta cell function, insulin sensitivity and glucose tolerance testing

towards higher ROC AUCs for individuals with impaired glucose tolerance relative to those with NGM than for individuals with impaired fasting glucose relative to NGM (data not shown). This is in line with the post-load glucose metabolism of individuals with impaired fasting glucose being normal, reflecting an adequate (compensatory) post-load BCF. Future studies that focus on estimates of insulin secretory function in prediabetes subtypes may provide novel insights into the aspects of BCF covered by the several BCF indices.

In line with previous findings [24, 25], discriminatory abilities of the oral DIs $\mathrm{CIR}_{30}$ and $\Delta \mathrm{I}_{30} / \Delta \mathrm{G}_{30}$ were significantly better than those of the isolated $\mathrm{BCF}$ indices in the current study. Moreover, discriminatory abilities of the oral DIs were better than those of the Matsuda index alone, especially the DIs of $\Delta \mathrm{I}_{30} / \Delta \mathrm{G}_{30}, \Delta \mathrm{CP}_{30} / \Delta \mathrm{G}_{30}$ and $\mathrm{CIR}_{30}$. This suggests that $\Delta \mathrm{I}_{30} / \Delta \mathrm{G}_{30}, \Delta \mathrm{CP}_{30} / \Delta \mathrm{G}_{30}$ and $\mathrm{CIR}_{30}$ contributed significantly to the discrimination of glucose metabolism groups, on top of insulin sensitivity. This indicates specific features of BCF irrespective of insulin sensitivity.

ROC analyses of logistic regression outcomes of the BCF indices with the Matsuda index as a covariate (using the probabilities predicted by the regression model) revealed similar results, as presented in Fig. 1 (data not shown). Theoretically, a hyperbolic function between BCF and insulin sensitivity has been suggested as a requirement to apply the DIs. In our data, such a hyperbolic function between any of the BCF indices and a measure of insulin sensitivity (e.g. the Matsuda index, HOMA-IR or the insulin sensitivity index $\left.\left(\mathrm{SI}_{0,120}\right)\right]$ was not present [data not shown]). This is in line with some other studies [26, 27], but there are studies that have established a hyperbolic function between BCF and insulin sensitivity [26, 28]. In addition, artificial relations between indices of $\mathrm{BCF}$ and insulin 

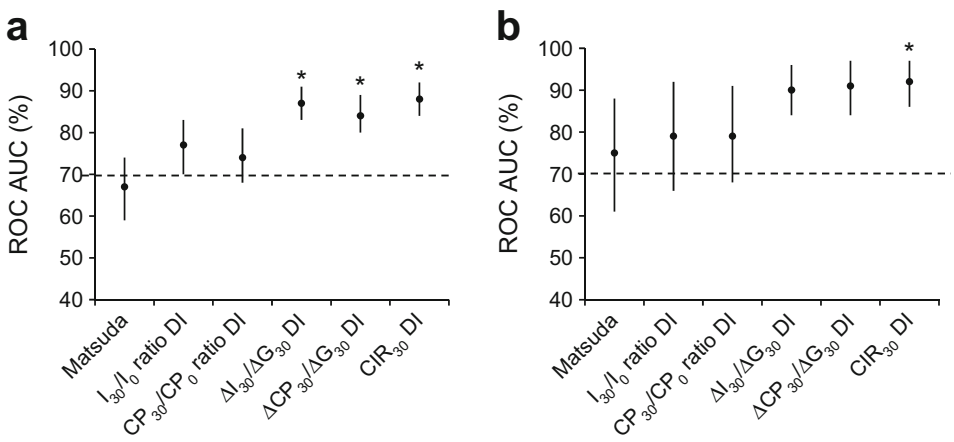

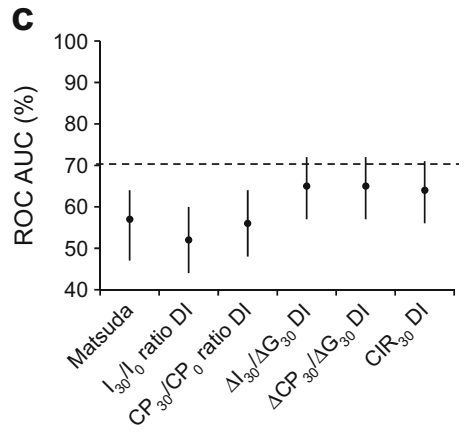

Fig. 1 ROC AUCs and corresponding 95\% CIs of the oral DIs for: (a) discriminatory abilities for incident type 2 diabetes mellitus (T2DM) in at-baseline non-T2DM; (b) discriminatory abilities for incident T2DM in at-baseline NGM; and (c) discriminatory abilities for incident prediabetes in at-baseline NGM, CODAM study, Maastricht, the Netherlands, 1999 2009. Dashed line, ROC AUC 50\%. * $p<0.05$ for ROC AUC vs Matsuda index alone

population may be smaller than in the general population, the discriminatory abilities of the BCF indices in the general population may be larger.

In summary, early-phase BCF indices obtained from an OGTT revealed those with the best abilities to discriminate glucose metabolism status. Overall, the C-peptidogenic index $\left(\Delta \mathrm{CP}_{30} / \Delta \mathrm{G}_{30}\right)$ had the best discriminatory ability. If the degree of insulin sensitivity is taken into account by calculating the DIs, the insulinogenic index $\left(\Delta \mathrm{I}_{30} / \Delta \mathrm{G}_{30}\right)$, the C-peptidogenic index $\left(\Delta \mathrm{CP}_{30} / \Delta \mathrm{G}_{30}\right)$ and $\mathrm{CIR}_{30}$ had the highest ability to discriminate glucose metabolism status. Based on our results, we recommend the $\mathrm{C}$-peptidogenic index $\left(\Delta \mathrm{CP}_{30} / \Delta \mathrm{G}_{30}\right)$ for assessing $\mathrm{BCF}$ in epidemiological studies. However, the preferred combination of BCF indices reflecting different aspects of insulin secretory function should be determined in view of the specific objectives and hypotheses of the study.

a relative advantage in terms of predictive power.

The present study benefits from the comparison of all available BCF indices in one study population, which includes individuals with NGM, prediabetes and newly diagnosed type 2 diabetes. Moreover, the study has a longitudinal set-up with 7 years of follow-up. Furthermore, the assessment of plasma $\mathrm{C}$-peptide concentrations enabled comparative analyses between BCF indices based on insulin and C-peptide concentrations. Some limitations also merit discussion. First, glucose metabolism status, BCF and insulin sensitivity were all obtained from a single OGTT [31]. We aimed to minimise autocorrelation between BCF and insulin sensitivity by using the Matsuda index, which is based on fasting and mean plasma insulin and glucose concentrations during the OGTT, rather than on concentrations at specific time points only. Although our interest was in discrimination, and not in association estimates, correlations between the BCF indices and the Matsuda index were very weak overall, and additional multicollinearity diagnostics (i.e. the variance inflation factor) were negative. Finally, CODAM participants have a higher risk of type 2 diabetes than the general population, so generalisability might be limited. However, as the differences in BCF between nondiabetic and type 2 diabetic individuals in the present study
Acknowledgements We thank L. Meertens (Department of Epidemiology, Maastricht University, Maastricht, the Netherlands) for her assistance with designing the graphics in the ESM.

Funding Part of this work was supported by Grants of the Netherlands Organization for Scientific Research (940-35-034) and the Dutch Diabetes Research Foundation (98.901).

Data availability The data that support the findings of this study are available from the corresponding author upon reasonable request.

Duality of interest The authors declare that there is no duality of interest associated with this manuscript.

Contribution statement LJCJdB and SJSS performed mathematical model analyses and statistical analyses, interpreted the data and wrote the manuscript. SJPME and PCD contributed to the conception and interpretation of the data and to data analyses, and participated in drafting the article and critically revising it for important intellectual content. AM and EF designed the mathematical model, provided support in performing mathematical analyses, contributed to the data quality of the mathematical analyses and made important contributions to the interpretation of the 
BCF data. MMJvG, CGS and CJHvdK contributed to data acquisition and study coordination. CDAS provided advice and contributed to the conception of the data, to data acquisition and to study coordination. All authors contributed to and/or provided critical comments and suggestions on the manuscript, reviewed the final draft of the manuscript and gave final approval of the version to be published. PCD is the guarantor of this work.

Open Access This article is distributed under the terms of the Creative Commons Attribution 4.0 International License (http:// creativecommons.org/licenses/by/4.0/), which permits unrestricted use, distribution, and reproduction in any medium, provided you give appropriate credit to the original author(s) and the source, provide a link to the Creative Commons license, and indicate if changes were made.

\section{References}

1. Bergman RN, Finegood DT, Kahn SE (2002) The evolution of beta-cell dysfunction and insulin resistance in type 2 diabetes. Eur J Clin Investig 32(Suppl 3):35-45

2. Cobelli C, Toffolo GM, Dalla Man C et al (2007) Assessment of beta-cell function in humans, simultaneously with insulin sensitivity and hepatic extraction, from intravenous and oral glucose tests. Am J Physiol Endocrinol Metab 293:E1-E15

3. Pacini G, Mari A (2003) Methods for clinical assessment of insulin sensitivity and beta-cell function. Best Pract Res Clin Endocrinol Metab 17:305-322

4. Ahren B, Pratley RE, Soubt M, Dunning BE, Foley JE (2008) Clinical measures of islet function: usefulness to characterize defects in diabetes. Curr Diabetes Rev 4:129-145

5. Matthews DR, Hosker JP, Rudenski AS, Naylor BA, Treacher DF, Turner RC (1985) Homeostasis model assessment: insulin resistance and beta-cell function from fasting plasma glucose and insulin concentrations in man. Diabetologia 28:412-419

6. Cersosimo E, Solis-Herrera C, Trautmann ME, Malloy J, Triplitt CL (2014) Assessment of pancreatic beta-cell function: review of methods and clinical applications. Curr Diabetes Rev 10:2-42

7. Kruijshoop M, Feskens EJM, Blaak EE, de Bruin TWA (2004) Validation of capillary glucose measurements to detect glucose intolerance or type 2 diabetes mellitus in the general population. Clin Chim Acta 341:33-40

8. van Greevenbroek MM, Jacobs M, van der Kallen CJ et al (2011) The cross-sectional association between insulin resistance and circulating complement $\mathrm{C} 3$ is partly explained by plasma alanine aminotransferase, independent of central obesity and general inflammation (the CODAM study). Eur J Clin Investig 41:372-379

9. World Health Organization (2006) Definition and diagnosis of diabetes mellitus and intermediate hyperglycaemia: report of a WHO/ IDF Consultation. WHO, Geneva

10. Kahn SE, Prigeon RL, McCulloch DK et al (1993) Quantification of the relationship between insulin sensitivity and beta-cell function in human subjects. Evidence for a hyperbolic function. Diabetes 42 : $1663-1672$

11. Matsuda M, DeFronzo RA (1999) Insulin sensitivity indices obtained from oral glucose tolerance testing: comparison with the euglycemic insulin clamp. Diabetes Care 22:1462-1470

12. Mari A, Schmitz O, Gastaldelli A, Oestergaard T, Nyholm B, Ferrannini E (2002) Meal and oral glucose tests for assessment of beta-cell function: modeling analysis in normal subjects. Am J Physiol Endocrinol Metab 283:E1159-E1166
13. Friedewald WT, Levy RI, Fredrickson DS (1972) Estimation of the concentration of low-density lipoprotein cholesterol in plasma, without use of the preparative ultracentrifuge. Clin Chem 18:499-502

14. Brouwers MC, Cantor RM, Kono N et al (2006) Heritability and genetic loci of fatty liver in familial combined hyperlipidemia. J Lipid Res 47:2799-2807

15. Jacobs M, van Greevenbroek MM, van der Kallen CJ et al (2011) The association between the metabolic syndrome and alanine amino transferase is mediated by insulin resistance via related metabolic intermediates (the Cohort on Diabetes and Atherosclerosis Maastricht [CODAM] study). Metab Clin Exp 60:969-975

16. Jacobs M, van Greevenbroek MM, van der Kallen CJ et al (2011) The association between the metabolic syndrome and peripheral, but not coronary, artery disease is partly mediated by endothelial dysfunction: the CODAM study. Eur J Clin Investig 41:167-175

17. Wendel-Vos GC, Schuit AJ, Saris WH, Kromhout D (2003) Reproducibility and relative validity of the short questionnaire to assess health-enhancing physical activity. J Clin Epidemiol 56: 1163-1169

18. DeLong ER, DeLong DM, Clarke-Pearson DL (1988) Comparing the areas under two or more correlated receiver operating characteristics curves: a nonparametric approach. Biometrics 44:837-845

19. Tape TG. The area under an ROC curve. Available from http://gim. unmc.edu/dxtests/roc3.htm, accessed 16 August 2016

20. Hanson RL, Pratley RE, Bogardus C et al (2000) Evaluation of simple indices of insulin sensitivity and insulin secretion for use in epidemiologic studies. Am J Epidemiol 151:190-198

21. Lorenzo C, Hazuda HP, Haffner SM (2012) Insulin resistance and excess risk of diabetes in Mexican-Americans: the San Antonio Heart Study. J Clin Endocrinol Metab 97:793-799

22. Festa A, Williams K, Hanley AJ, Haffner SM (2008) Beta-cell dysfunction in subjects with impaired glucose tolerance and early type 2 diabetes: comparison of surrogate markers with first-phase insulin secretion from an intravenous glucose tolerance test. Diabetes 57:1638-1644

23. Gerich JE (1997) Metabolic abnormalities in impaired glucose tolerance. Metab Clin Exp 46:40-43

24. Abdul-Ghani MA, Williams K, DeFronzo RA, Stern M (2007) What is the best predictor of future type 2 diabetes? Diabetes Care 30:1544-1548

25. Ram J, Snehalatha C, Selvam S et al (2015) The oral disposition index is a strong predictor of incident diabetes in Asian Indian prediabetic men. Acta Diabetol 52:733-741

26. Retnakaran R, Shen S, Hanley AJ, Vuksan V, Hamilton JK, Zinman B (2008) Hyperbolic relationship between insulin secretion and sensitivity on oral glucose tolerance test. Obesity 16:1901-1907

27. Solomon TP, Malin SK, Karstoft K et al (2014) Determining pancreatic beta-cell compensation for changing insulin sensitivity using an oral glucose tolerance test. Am J Physiol Endocrinol Metab 307: E822-E829

28. Utzschneider KM, Prigeon RL, Faulenbach MV et al (2009) Oral disposition index predicts the development of future diabetes above and beyond fasting and 2-h glucose levels. Diabetes Care 32:335-341

29. Ferrannini E, Mari A (2014) beta-Cell function in type 2 diabetes. Metab Clin Exp 63:1217-1227

30. Ferrannini E, Mari A (2004) Beta cell function and its relation to insulin action in humans: a critical appraisal. Diabetologia 47:943-956

31. Mari A, Pacini G, Brazzale AR, Ahren B (2005) Comparative evaluation of simple insulin sensitivity methods based on the oral glucose tolerance test. Diabetologia 48:748-751

32. Levy JC, Matthews DR, Hermans MP (1998) Correct homeostasis model assessment (HOMA) evaluation uses the computer program. Diabetes Care 21:2191-2192

33. Lowry R (2001-2015) Significance of the difference between the areas under two independent ROC curves. Available from http://vassarstats.net/roc_comp.html, accessed August 2015 
34. Perley M, Kipnis DM (1966) Plasma insulin responses to glucose and tolbutamide of normal weight and obese diabetic and nondiabetic subjects. Diabetes 15:867-874

35. Phillips DI, Clark PM, Hales CN, Osmond C (1994) Understanding oral glucose tolerance: comparison of glucose or insulin measurements during the oral glucose tolerance test with specific measurements of insulin resistance and insulin secretion. Diabet Med 11:286-292

36. Saad MF, Knowler WC, Pettitt DJ, Nelson RG, Mott DM, Bennett PH (1988) The natural history of impaired glucose tolerance in the Pima Indians. N Engl J Med 319:1500-1506

37. Wareham N, Byrne C, Hales C, Phillips D (1995) The 30 minute insulin incremental response in an oral glucose tolerance test as a measure of insulin secretion. Diabet Med 12:931
38. Sluiter WJ, Erkelens DW, Reitsma WD, Doorenbos H (1976) Glucose tolerance and insulin release, a mathematical approach I. Assay of the beta-cell response after oral glucose loading. Diabetes 25:241-244

39. Stumvoll M, Mitrakou A, Pimenta W et al (2000) Use of the oral glucose tolerance test to assess insulin release and insulin sensitivity. Diabetes Care 23:295-301

40. Hansen T, Drivsholm T, Urhammer SA et al (2007) The BIGTT test: a novel test for simultaneous measurement of pancreatic betacell function, insulin sensitivity, and glucose tolerance. Diabetes Care 30:257-262

41. Levine R, Haft DE (1970) Carbohydrate homeostasis. N Engl J Med 283:237-246 